\title{
Disruptive Design Innovation Reflections on the Relationship of Design, Science and Art
}

The title of designer conveys a large number of historical, cultural, philosophical drivers and working practises that effectively range from the traditional engineer through to the individual interested in personal expression. The considerable differences originate and have evolved for a variety of reasons. The range is from capitalist necessity through to social inclusion. Today, the designer needs to have the ability to understand significant changes in technology, art and science as well as being an astute observer of human behaviour. Ultimately, the designer will need to convert ideas into objects and systems that people can understand and use. It is important to consider serendipitous design and disruptive design as it often involves risk taking and may be unpredictable in character. Disruptive design innovation can improve a design in ways that the customer or a market does not expect. The authors suggest a refreshing approach to design that is inclusive in purpose to enrich the act of designing and advocate a greater correlation between the art, sciences and design in reflecting the values, virtues and methods of working and the principles that guide the methodologies and processes which can be correlated into a coherent whole and with a clearer focus.

Keywords: Disruptive Design, Technology, Art \& Science, Serendipitous Design

\section{Introduction}

Early in 2002 the writer John Heskett stated (Heskett, 2002) 'Design has been widely transformed into something banal and inconsequential'. Despite this honest appraisal support for a cross over between disciplines has been mooted. Before articulating the rationale for interdisciplinarity it is important to contextualise the importance of how we think.

If we challenge our thought process our cultural, scientific and linguistic reference points: how up to date of design are we, honestly? There are numerous cultures and boundaries in theory \& practice: or do we still rely on a full back position of re-iterating something that we learned a long time ago? This is not to suggest that there is not a real value in understanding key designs or seminal texts and formulae; conversely, it is suggesting that the classical notion of various disciplines be maintained, but not as an academic mantra or form of intellectual bling, but something that is to be used as a yardstick or benchmark and has credibility, kudos and relevance.

Moreover, there is a need to arrest our pre conceptions and working processes and try something different, within our own context and apply it to other areas also.We follow processes of (Pugh, S. 1990), and (Lawson, B. 2005) in almost parochial manner. Yes, they are tried and tested within design itself, but they are also a framework which designers need to challenge; not because they are wrong, but because they represent some of the canons within the provenance of design. Any designer knows implicitly that challenging the intellectual and the practise of design will ultimately move the profession forwards and nurture some form cognitive dissonance (Lidwell, W. Holden, K. \& Butler,J. 2003) within staff, students and working designers.

In addition, apart from science, art and design being correlated there is also a genuine need for undergraduates to have a greater understanding of the skills to mange the design process in a holistic manner (Hands, D. 2009.). Indeed, there has to be some form of correlation between these to facilitate the encouragement of young designers to consider an ontological landscape of some description (Dunn, A. 2005) .If design can be characterised, one of the main characteristics must be the maintenance of some degree of independence from the main stream when it is possible. Therefore, it would be wise to consider historical precedence. The critical theory originating from the Frankfurt School always emphasised that its function in part was to resist the commercial world (Strinati D, 2003) 


\section{Counter argument}

Historically, there are a number of individuals, movements and canons of thought that one can refer to when considering the importance of understanding historical precedents. Max Horkheimer, the German philosopher in his inaugural address at the Frankfurt School described the importance of critical theory and how history - as a discipline - needed to include a number of areas and subjects including: philosophy, history, sociology and economics with the purpose of explaining the relationship between the individual and society. In many respects he was echoing the structuralist view of attempting to correlate the human sciences into one methodology and method with is bases in Sausserian linguistics. According to (Strinati,D. 2003) critical theory at the Frankfurt School was a form of resistance to commercial impulses and capitalist production and the hold of the commodity fetish (Strinati D, 2003). Nevertheless, the topic of this paper is not anti capitalist but questioning whether the pursuance of the profit margin is helping or hindering the promotion of something innovative.

Accordingly (Sparke, P. 2004) has stated that Raynor Banham's seminal essay written in 1958 entitled, 'The Throw Away Society' challenged contemporary design and art thinking establishing that there was no intrinsic link between geometric simplicity and function. Banham was an Engineer who had studied at St Martins School of Art and had a significant influence upon the development of the pop culture in the United Kingdom, especially in the way that products were represented. Banham, argued that, 'we live, he explained in a throw away economy, culture in which the most fundamental classification of our ideas are worldly possessions is in terms of relative expendability'(Banham, R. 1958:183). Banham's central theses is still being indirectly referred to today; however, in a recent article (Lorenzo,T. 2006) focused upon the, 'British Designers Accused of Creating a Throw Away Culture'. The text poses the uncomfortable suggestion that designers are the perpetuators and they - the designers - are victims, for the sake of employment.

\section{Change}

Consequently, there was a need for change. The premise of a different approach varied from a number of different disciplines ranging from a natural change to the radical re-think of traditional Engineering practises. In 1994 Bucharelli produced a book entitled Design Engineers in which he refers to (Bucharelli, 1994) to how a telephone and a chair work; raising questions about technological literacy and power. Several years later a number of visual designers were signatories to a statement that questioned why design was simply serving consumerism and advocated a worthwhile use of their skills. The charter was published in Adbuster, the AIGA journal Blueprint etc. During the same period, a different approach was being taken towards design IDEO in the United States. In the Times Higher Educational magazine McCloskey in an article advocating that disciplines unite stated that, 'Innovation not investment or trade or exploitation, caused the industrial revolution. That is, the production function leapt up and up and up from human ingenuity. Plate glass, Re-enforced concrete. Modern Universities. Ideas. Look around you' (McCloskey, D. 2010)

Nevertheless, the UK government has sponsored research in this area. This is a relatively new and developing area for many to venture into. Liebenau, in his report from the UK government in 2007 clarified a number of areas involving disruptive design. He articulates that there is always a problem with people taking a range of views (Liebebau J., 2007,: 3) but he also states that innovators must be recognised at an early stage. He suggests that experimentation is important, but is also cautious when mentioning that diffusion is also difficult to measure.

Alternatively, a number of areas that need to be revisited that relate to the correlation of working practises concerning design science and art. Each discipline contains canons of thought, methodological drivers and values. The methods of measuring and manufacturing differ in character that need to be ring fenced for obvious reasons, however they also need to be drawn upon when necessary to support the art of designing. The richness of the subjects and the attributes we ascribe to them should be used to serendipitously occasionally in the process of design, taking risks where possible in these approaches will make 'us' think and respond differently and instead of producing a homogeneous object of design something different, new and relevant. 
Both academic and students within the product design subject area have worked with other colleague's and students on a large number of research projects that cross the boundaries of science, design and art. Often this involves staff and students working outside of their normal areas of expertise and knowledge. One current example involves product design staff and postgraduate students working with clinicians and surgeons on innovative medical devices utilising smart materials and technologies.

\section{Case Study - Medical devices}

Facial paralysis caused by strokes and other medical conditions can have a very large impact on a patient both physically and mentally; individuals who have had severe facial nerve injury experience degraded self-image and loss of self-esteem. Current research has focused on the potential utilisation of a Shape Memory Alloy (SMA) to replace the function of the Facial Nerve.

Although SMA's have been used extensively for a number of clinical and medical applications, the use of SMA's for corrective/cosmetic surgery is limited. described an SMA implant for corrective surgery to pin back a patients ears' suggesting that this procedure could be carried out with a local anaesthetic and completed in minutes by a nurse was described by (Kang N, 2009). Senders and Tollefson (2009) suggest an approach utilising artificial polymer muscles as an implant to help patients regain control over partially or fully paralysed eyelids after suffering spinal injuries or nervous disorders such as Bell's Palsy. Senders and Tollefson stated; "The face is an area where natural appearing active prosthetics would be particularly welcome". page number Phil ?

Research has investigated the development of an interface system that controls the input from an Electromyography (EMG) muscle sensor into an output to control a Shape Memory Alloy (SMA) actuator. The proposed system used to regain limited control of the patients smile. Development utilising an animatronic head shown in Figure 1.0 will provide the realisation of this application using a number of smart materials and ultimately confirm its potential viability in corrective surgical practise. This work provides a firm foundation for further research and development for the potential integration of SMA's within the human body by demonstrating that control of SMA's can be gained using an EMG interface. (Breedon and Vloeberghs, 2009)

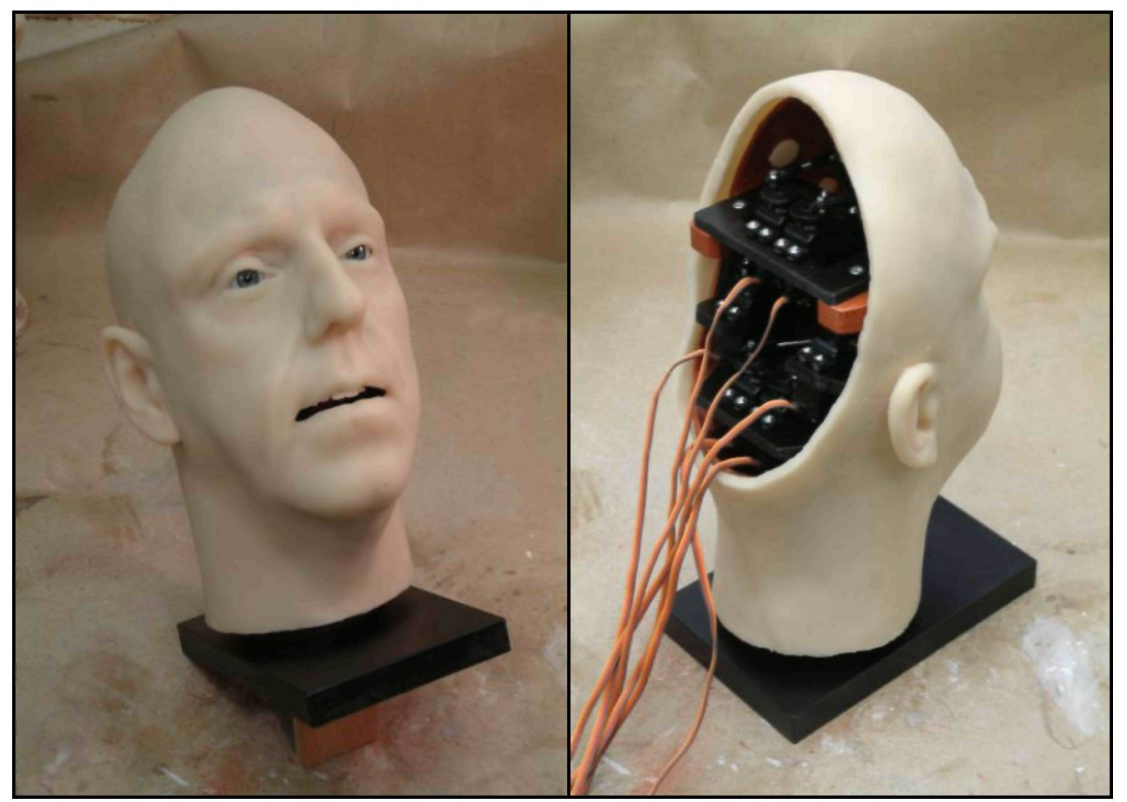

Figure 1.0: Animatronic head built for initial testing 
A user centred design approach as an adapted design methodology and as implemented for this case study can provide real benefits in terms of medical product design. Orthopaedic device design and development provides a good example. Orthopaedic devices must be designed to accommodate dynamic environments and varied surgical processes. In addition, meeting with the surgeon to discuss spatial relationships and provide the opportunity to touch the instrument can provide useful verbal feedback. To aid this process designers often produce a 3D model, which can be modified quickly and easily, allows the development of a range of fabricated models for a single device specification.

Another important aspect of surgical device design is to define the parameters associated with dimension, overall function and other device variables in perspective, and to use this information to design a device that complements surgical technique. This process includes kinaesthetic learning or intelligence from or within the clinical environment and incorporating this intelligence into the design concepts.

\section{Conclusion}

The purpose of this paper was to challenge designers to begin to encourage more disciplines to design rather than make all of the usual and predictable references to the obvious relationships. The connections that reflect that knowledge and processes have moved on from the mechanics of design, mined the aesthetics and matured from anthropometrics and ergonomics into behavioural analysis. But, there is also a constant need to remind ourselves to think about design. To explore paths of bifurcating directions towards some form of abstraction is not difficult to develop. However, there is a tired feeling that resonates from some key areas of design linked to well-worn phrases and meanings that are still being perpetuated.

This paper is not a call to negate what we know; but a suggestion that there is a need to encourage cognitive dissonance rather than refer to embroidered concepts that we are all too familiar with, that should remain within the domain of obscure journals of coffee table books. The authors of this paper are senior lecturers in design originating from art, science and design backgrounds. They represent over 40 years experience in teaching, research and working with industry. They advocate that design and the various disciplines need to be understood, holistically from the traditional, contemporary and the future perspective. They also believe that there is a need to challenge traditionalists and maintain that randomness; accident and disruption need to be a part of the design process. Therefore, designers need to drive the agenda for design to facilitate progression. 


\section{References}

Breedon P \& Vloeberghs M., 2009, Application of shape memory alloys in facial nerve paralysis. AMJ 2009, 1, 10, 36-43. Doi 10.4066/AMJ.2009.59

Bucciarelli L in Clark, H, Brody D., 2009, Designing Engineers, Design Studies, A Reader, Berg, MPG Books UK

Dunn A. 2005, Hertzian Tales, MIT.USA

Hands D. 2009. Vision and Values in Design Management. AVA Production.

Heskett J. Design 2002, Design, Oxford University Press, Ashford cover Press Ltd, Gosport, Hampshire

Kang N, "How to coax prominent ears into line", New Scientist, David Robson (Ed.), $15^{\text {th }}$ September 2007:32. In press article

Lorenzo T. in Clark, H, Brody, D., 2009, Design Studies, A Reader, Berg, MPG Books UK

Liebebau J., 2007, Innovation Trend: Prioritising Emerging Technologies Shaping the UK 2017.HMSO

Lawson B, 2005, How Designers Think: The Design Process Demystified, Architectural Press

Lidwell W.Holden, K \& Butler J., 2003 'cognitive dissonance', Universal Principles of Design,.

McCloskey D., 2010, Modern Universities. Ideas. Look around you', Times, Printed in the UK

Senders C \& Tollefson T, Innovation: Robotic faces... for Humans, New Scientist, $16^{\text {th }}$ February 2009 , Simonite T (Ed). In press article

Mc Dermott K. 2007, 'Critical Design 'Routledge, TJ International, Padstow, Cornwall

Pugh S, 1990,Total Design: Integrated Methods for Successful Product Engineering Prentice Hall Rockport, China

Sparke P., 2004, Design \& Culture (1900 to the present) Rout ledge, MPG Books Ltd, Bodmin

Strinati D. 2003, An Introduction to the Theories of Popular Culture, Routledge, MPG Books Ltd, Bodmin, Cornwall 
